\title{
Corrigendum: Inertial-confinement fusion with lasers
}

R. Betti and O. A. Hurricane

Nature Physics 12, 435-448 (2016); published online 3 May 2016; corrected after print 1 June 2016.

In the version of this Review Article originally published, the size of the gold hohlraum described in the section 'Laser indirect drive' was incorrect and it should have read ' $5.75 \mathrm{~mm}$ in diameter.' This has been corrected in the online versions after print 1 June 2016. 